\title{
Correction to: Trends and spatial pattern recognition of warm season hot temperatures in Saudi Arabia
}

\section{Ali S. Alghamdi ${ }^{1}$ (D) John Harrington $\mathrm{Jr}^{2}$}

Published online: 22 June 2019

(C) Springer-Verlag GmbH Austria, part of Springer Nature 2019

\section{Correction to: Theoretical and Applied Climatology} https://doi.org/10.1007/s00704-019-02860-6

The original version of this article unfortunately contained a mistake. The presentation of Fig. 4 was incorrect. The corrected figure is given below.

The original article has been corrected.

The online version of the original article can be found at https://doi.org/ 10.1007/s00704-019-02860-6

Ali S. Alghamdi

aorifi@ksu.edu.sa

1 Department of Geography, College of Art, King Saud University, P.O. BOX 2456, Riyadh 11451, Kingdom of Saudi Arabia

2 Department of Geography, Kansas State University, 1002 Seaton Hall, Manhattan, KS 66506, USA 

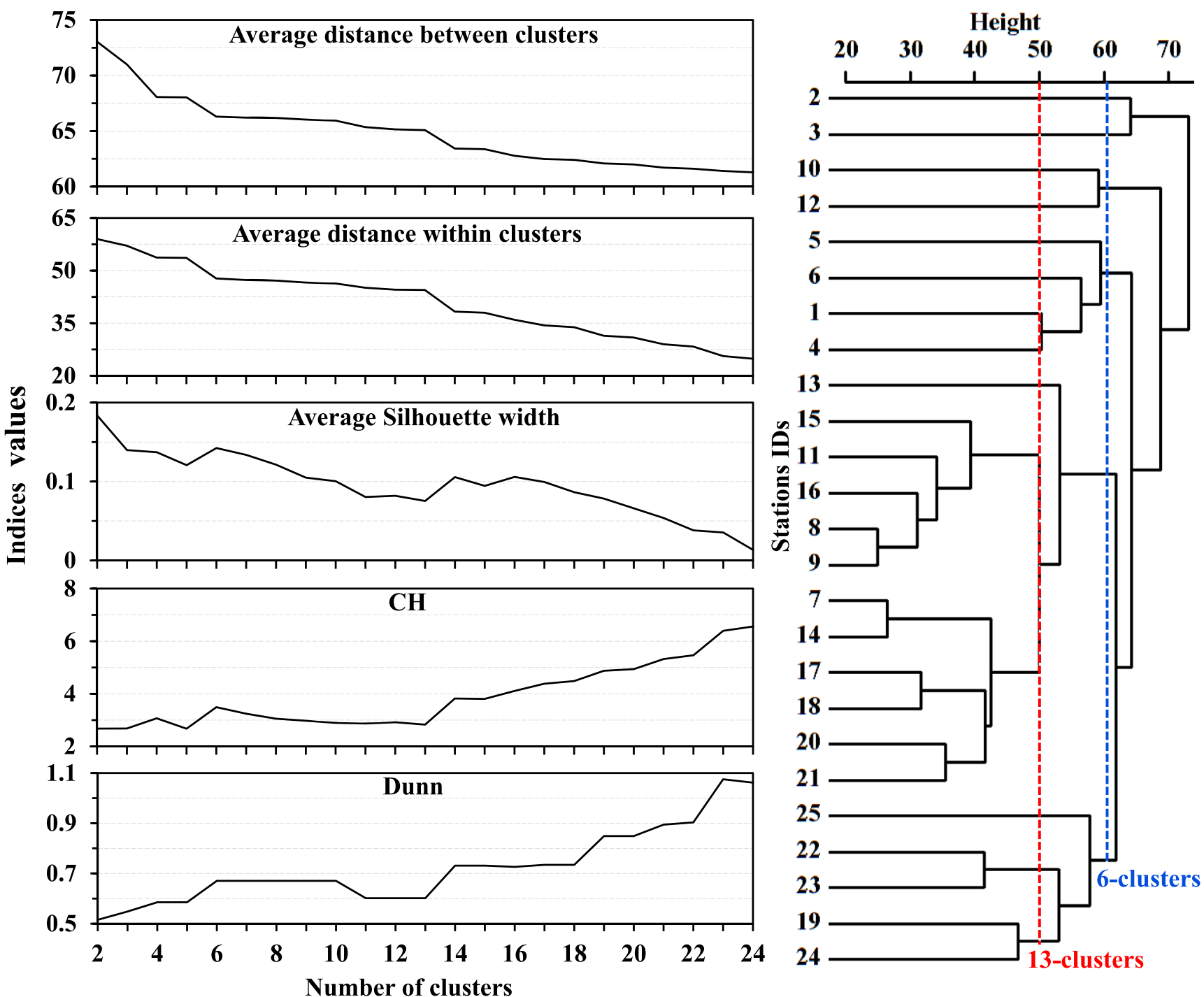

Fig. 4 Validity indices for the HD indicator (left) and cluster dendrogram (right) along with stations IDs

Publisher's note Springer Nature remains neutral with regard to jurisdictional claims in published maps and institutional affiliations. 